\title{
Capítulo
}

3

\section{Desenvolvendo Jogos Educacionais Digitais Inovadores e Instigantes com o Framework PlayEduc}

\author{
Samanta F. Aires, Jorge F. R. Barbosa e Charles A. G. Madeira
}

\begin{abstract}
With the constant growth of the game industry in Brazil and in the world, digital games seem to be one of the most used technologies, being part of the routine of digital-native student generation. Digital Educational Games (DEG) are specially considered as a promising strategy for the teaching and learning process. However, many of the DEG are stereotyped as boring by the students, since they are focused only on the pedagogical context, forgetting the emotional context that makes entertainment games interesting for the players. So, there is a need to provide better quality to the DEG since their conception, aligning entertainment within education in a balanced way. In order to contribute in this sense, some methodological initiatives, well adapted to the development of DEG, have been proposed in recent years. PlayEduc framework is one of them, being able to assist with the design process of DEG adapted to the interests of students and teachers. Also, PlayEduc is applied in association with the Design Thinking for Educators approach, promoting the knowledge construction about strategies for designing innovative and exciting DEG.
\end{abstract}

\section{Resumo}

Com o constante crescimento da indústria de jogos no Brasil e no mundo, os jogos digitais têm se mostrado como uma das tecnologias mais utilizadas, fazendo parte da rotina dos estudantes da geração atual, conhecida como nativos digitais. Os Jogos Educacionais Digitais (JED), particularmente, já são considerados como uma estratégia promissora para o processo de ensino e aprendizagem. No entanto, muitos desses jogos são estereotipados como chatos pelos alunos, pois são focados apenas no contexto pedagógico, negligenciando o contexto emocional que tornam os jogos voltados ao entretenimento interessantes aos jogadores. Dessa forma, existe a necessidade de prover uma melhor qualidade aos JED desde a sua concepção, alinhando o entretenimento com a educação de uma forma balanceada. Visando contribuir neste sentido, algumas 
iniciativas de metodologias, bem adaptadas ao desenvolvimento de JED, têm sido propostas nos últimos anos. Uma delas é o framework PlayEduc que se propõe a auxiliar no processo de concepção de JED adaptados aos interesses dos alunos e professores. Para isso, o PlayEduc é aplicado em conjunto com a abordagem do Design Thinking para Educadores, construindo o conhecimento sobre estratégias para conceber JED inovadores e instigantes.

\subsection{A Indústria de Jogos e a Produção de Jogos Educacionais Digitais}

A indústria de jogos vem ganhando mais relevância a cada ano. Atualmente já é uma das indústrias mais lucrativas do entretenimento, ultrapassando a do cinema e da música, tendo gerado uma receita de cerca de US\$ 120 bilhões em 2019, a maior parte oriunda dos jogos digitais [Superdata 2020a]. Em relatório mais recente, a Superdata [2020b] mostrou que a indústria dos jogos digitais faturou US\$ 82,8 bilhões nos primeiros oito meses de 2020, um crescimento de 13\% em comparação ao mesmo período de 2019.

Esses números são um reflexo do crescimento no consumo de jogos digitais mobile, decorrentes da popularização dos dispositivos móveis. Dados do relatório da Pesquisa Game Brasil 2020 mostram que a plataforma mais utilizada atualmente pelos jogadores do país é o smartphone [PGB 2020]. Além disso, a maior parte da receita de jogos digitais em 2019 também veio desses aparelhos [Superdata 2020a], conforme apresenta a Figura 1.

\section{Digital games revenue reached $\$ 109.4 \mathrm{~B}$ in 2019 , up 3\% year-over-year}

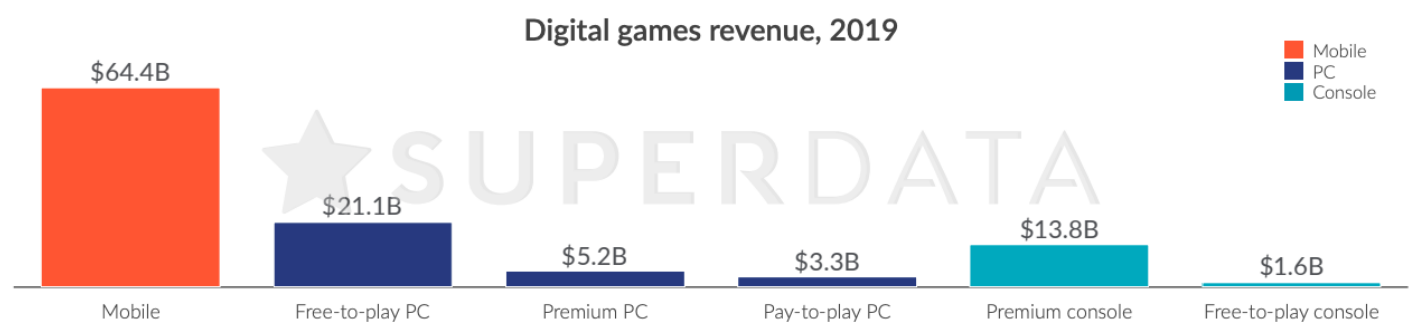

Figura 1. Receita da indústria de jogos digitais por plataforma no ano de 2019. Fonte: Superdata, 2019

Os smartphones facilitaram o acesso aos jogos de diversos gêneros e, com o aperfeiçoamento de seus hardwares e softwares, esses aparelhos já apresentam grande capacidade de processamento e armazenamento, permitindo assim que jogos mais elaborados possam ser produzidos para serem jogados neste tipo de plataforma.

Esse fato não é diferente no cenário brasileiro, com 75,7 milhões de jogadores assíduos em 2018, se apresentando em $1^{\circ}$ lugar na América Latina e em $13^{\circ}$ a nível global no ranking de consumidores de jogos digitais [Brasil 2018].

A indústria de desenvolvimento de jogos no Brasil também vem recebendo incentivos, com o surgimento de diversas empresas e desenvolvedores de jogos independentes. O $2^{\mathbf{o}}$ Censo da Indústria Brasileira de Jogos Digitais [Brasil 2018] divulgou que entre 2016 e 2017 foram produzidos cerca de 1718 jogos no País, sendo 785 destes voltados para o entretenimento, 874 voltados principalmente para a educação e o treinamento (jogos sérios), e 59 de outros tipos, o que significa mais de metade dos jogos produzidos com viés educacional (Figura 2). 
Percebe-se com esses dados que já é dada grande importância aos jogos educacionais digitais, que estão sendo cada vez mais utilizados como estratégia instrucional pelos educadores, devido ao seu grande potencial para o processo de ensino e aprendizagem [Petri et al. 2016; Gee 2009; Prensky 2012; Mattar 2010], assim como também pela familiarização dos alunos-jogadores com essa tecnologia [Prensky 2001].

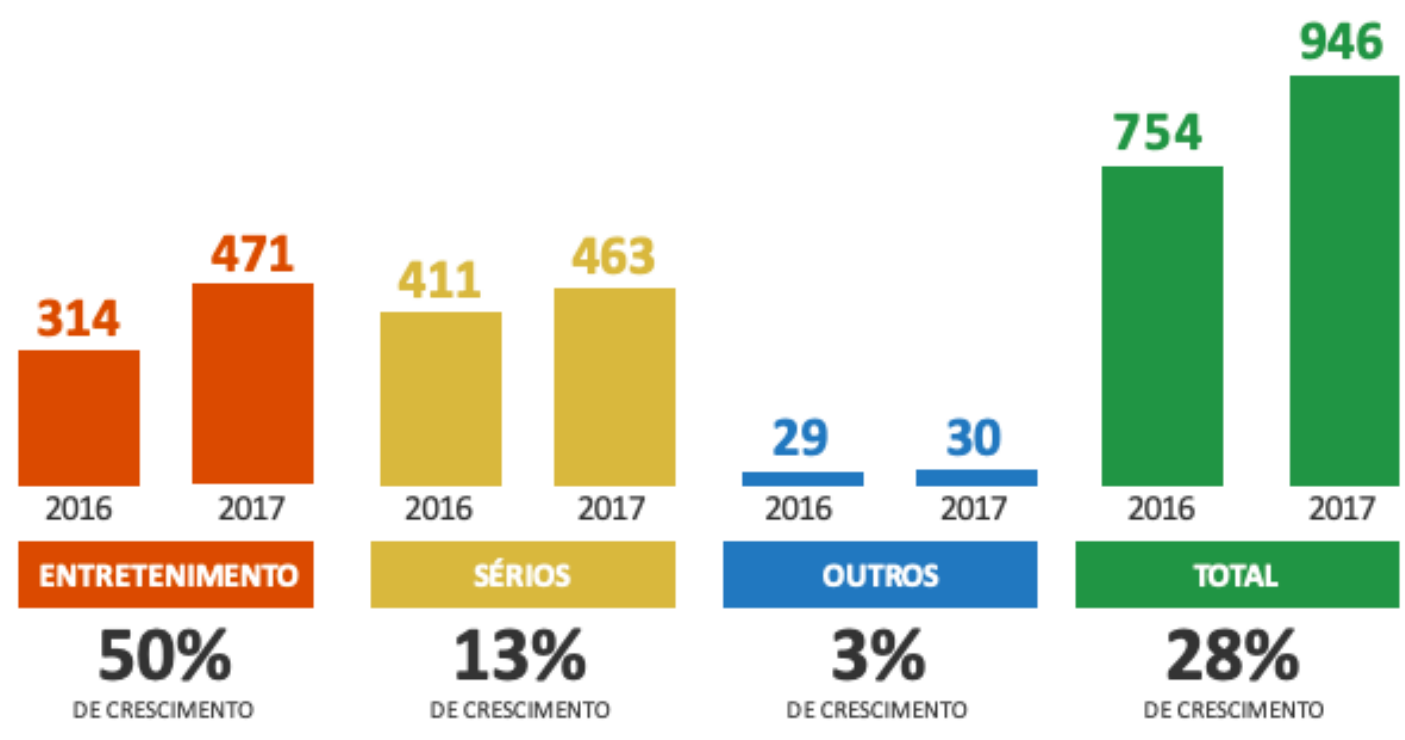

Figura 2. Número de jogos digitais desenvolvidos por categorias nos anos de 2016 e 2017. Fonte: 2o Censo da IBJD, 2018

\subsection{Potencial Educacional dos Jogos Digitais}

A utilização dos jogos digitais e de suas potencialidades como atividades pedagógicas vem crescendo significativamente ao longo dos anos [Gee 2009]. Koster [2013] afirma que todos os jogos podem ser considerados educacionais, pois proporcionam a aquisição de habilidades úteis na vida real, compondo ambientes atraentes e interativos que capturam a atenção do jogador ao oferecer desafios que exigem níveis crescentes de destreza e habilidades [Savi e Ulbricht 2008].

A utilização de jogos digitais na educação possibilita não somente a modernização do processo de ensino e aprendizagem, como também instiga cada vez mais os alunos a buscarem e a participarem da construção do seu próprio conhecimento [Fernandes et al. 2018].

Os Jogos Educacionais Digitais (JED) são aqueles voltados ao ensino de algum conteúdo ou habilidade, e podem ser definidos como softwares que oferecem conteúdos e atividades práticas, com objetivos educacionais baseados na recreação e no conhecimento [Santana 2018].

Através dos JED, os alunos se sentem mais motivados em aprender, pois os jogos promovem uma nova forma de interação do ser humano com as máquinas, possibilitando um nível mais profundo de interatividade [Mattar 2010] e se tornando ferramentas bastante promissoras para o processo de ensino e aprendizagem.

Existem alguns elementos indispensáveis aos jogos digitais que os tornam divertidos e cativantes para os jogadores. No contexto dos JED, o fato de inserir conteúdo 
educacional não se mostra por si só suficiente para gerar o engajamento dos alunos, pois os objetivos pedagógicos precisam ser inseridos em um contexto e situação de ensino baseados em uma metodologia que oriente o processo, através da interação, da motivação e da descoberta, facilitando a aprendizagem dos conteúdos e a aquisição de habilidades [Prieto et al. 2005].

Dessa forma, é necessário que os JED sejam bem elaborados e estruturados desde a sua ideia de concepção inicial, promovendo assim uma boa qualidade. Para isso, eles devem proporcionar um alinhamento adequado entre os elementos de mecânica, estética, narrativa e tecnologia, conforme indicado na Tétrade Elementar de Schell [2008], também tratando do entretenimento e da pedagogia para produzir jogos educacionais que demonstrem efetividade nos resultados obtidos no processo de ensino e aprendizagem.

\subsection{Problemática na Aplicação de Jogos na Educação}

Ao se fazer um recorte dos JED utilizados em sala de aula, é possível constatar que os alunos não conseguem se motivar e se engajar da mesma forma que se motivam e se engajam com os jogos voltados ao entretenimento, sendo seu uso caracterizado pelo baixo envolvimento do aluno-jogador e pela baixa qualidade na aprendizagem [Prensky 2012].

Apesar das potencialidades apresentadas em seu uso, muitos JED não têm se mostrado eficazes pois, além de serem considerados chatos pelos alunos - por ter foco no conteúdo pedagógico, deixando o entretenimento como algo secundário, também pecam no seu objetivo primário de ensinar [Costa 2008]. Alguns podem até mesmo ser definidos como atividades de fixação de conteúdo meramente apresentadas de forma digital [Barbosa e Madeira 2019].

Com isso, tanto alunos quanto professores têm preferido utilizar jogos voltados ao entretenimento para auxiliar no processo de ensino e aprendizagem, pois tendem a ser mais eficazes que os jogos educacionais em si [Costa 2008].

Um dos fatores que contribuem para esta problemática é o fato de que os JED são comumente desenvolvidos de modo ad-hoc, não seguindo uma metodologia de desenvolvimento formalizada e sendo geralmente superficialmente avaliados em relação ao seu impacto no processo de ensino e aprendizagem [Battistella e Wangenheim 2016]. Há então uma carência de estudos e ferramentas capazes de auxiliar o processo de desenvolvimento dos jogos educacionais digitais, que gere um produto eficaz e que congregue de forma harmônica as características dos jogos digitais com o design instrucional [Paz 2019; Barbosa 2018].

Diante disso, é necessário buscar metodologias e instrumentos para formalizar e auxiliar o processo de desenvolvimento de JED, visando torná-los mais atrativos para os alunos, alinhando tanto os aspectos pedagógicos necessários para o processo de ensino e aprendizagem, quanto os aspectos de entretenimento que tanto atraem os jogadores de qualquer idade.

\subsection{Processo de Desenvolvimento de Jogos Digitais}

O processo de desenvolvimento de jogos digitais requer uma equipe multidisciplinar, pois envolve diversas áreas de conhecimento, como programação, artes, design e música, que se complementam para produzir um produto de boa qualidade de acordo com os padrões atuais de mercado [Araújo et al. 2018]. 
Além disso, o processo pode variar, dependendo do orçamento, tamanho da equipe, finalidade do jogo, plataforma, público-alvo, gênero, etc. Contudo, há alguns passos comuns, com objetivos que devem ser seguidos para o desenvolvimento de qualquer jogo digital, sendo eles: pré-produção, produção, testes e pós-produção (ver Figura 3). O sucesso de cada passo depende da execução do passo anterior, refletindo diretamente no resultado do produto do jogo [Chandler 2012].

Na etapa de pré-produção é realizado o planejamento do projeto do jogo, iniciando com a concepção da ideia geral (game design), levantando requisitos e definindo o público-alvo, o gênero, coletando referências de personagens, opções de narrativa, entre outros elementos. Essa etapa é finalizada com a produção das documentações relacionadas, como o Game Design Document (GDD ou Documento de Projeto do Jogo) que é um documento de referência para toda a equipe envolvida no processo de desenvolvimento.

$\mathrm{Na}$ etapa de produção é realizada a implementação propriamente dita do projeto do jogo planejado na etapa anterior, que consiste tanto na tangibilização dos assets, que é feita por meio de ferramentas de modelagem, texturização, sonorização, entre outras, quanto na programação da interface e das mecânicas, que geralmente é feita por meio de uma Game Engine (ou Motor de Jogos).

Em seguida, na terceira etapa, são realizados diversos tipos de testes, desde aqueles referentes às funcionalidades do jogo até os que avaliam a sua usabilidade e jogabilidade.

A etapa de pós-produção é responsável pela finalização, fazendo um levantamento sobre o que funcionou ou não no desenvolvimento do jogo, visando prover melhorias e atualizações no jogo através da disponibilização de novas versões.

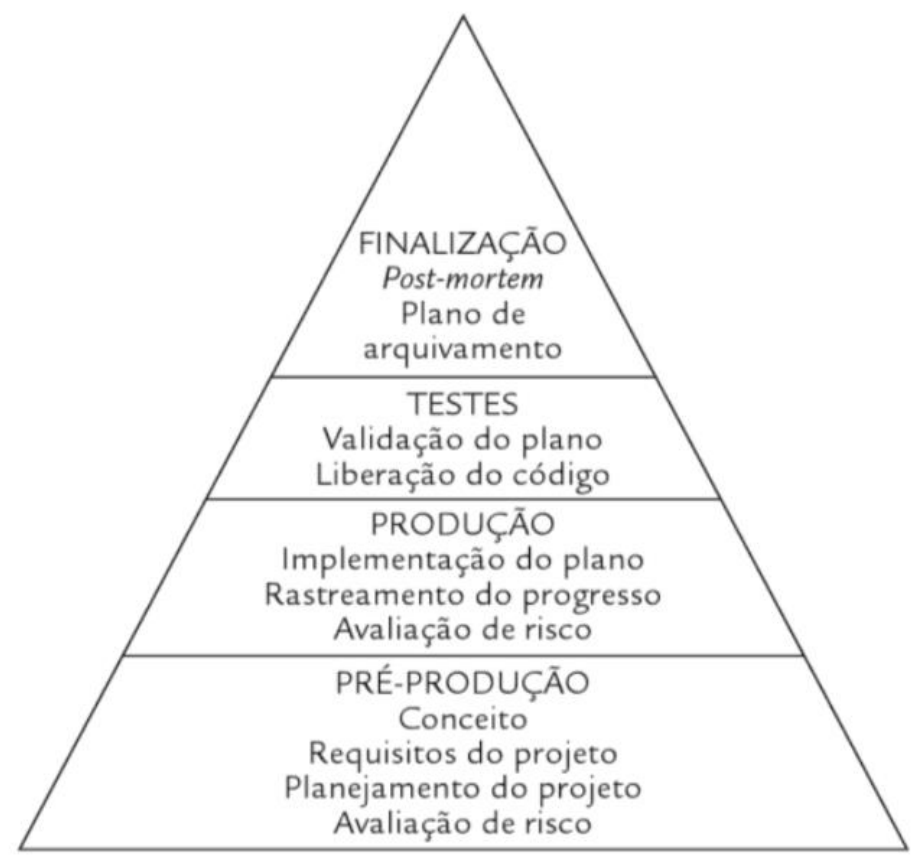

Figura 3. Ciclo Básico de Produção de Jogos. Fonte: Chandler, 2012

O processo de desenvolvimento dos JED difere daquele dos jogos voltados ao entretenimento no tange a necessidade de integração entre os aspectos de diversão e os 
objetivos pedagógicos do jogo, de modo a promover uma boa experiência para os jogadores. No entanto, as etapas citadas anteriormente também fazem parte da produção dos JED, sendo adicionado nos objetivos de cada fase a concepção, análise e rastreio contínuo sobre como estão inseridos os conteúdos educacionais no jogo, visto que esses são de extrema relevância nos JED.

Dessa forma, a etapa de pré-produção se mostra como uma fase crítica na produção de jogos, pois nela é realizado todo o planejamento do jogo, desde como ele será a quais elementos apresentará. Ademais, nos JED é preciso definir como o conteúdo educacional será inserido, de forma a promover uma experiência de jogo interessante e divertida ao aluno, ao mesmo tempo em que promove o seu aprendizado. Portanto, é de grande importância que essa etapa seja bem executada, para promover um produto que interesse ao aluno.

\subsection{Influência do Game Design no Resultado dos JED}

O Game Design (ou projeto de jogo) é fundamental para iniciar qualquer projeto de desenvolvimento de jogos, pois define a concepção do jogo, o estilo, público alvo, narrativa, mecânica, personagens, cenários, objetos, fases, níveis de dificuldade, sonorização, entre outros e, considerando o contexto de um jogo educacional digital, também seus aspectos pedagógicos [Fernandes et al. 2018].

Para Schell [2008], o responsável pelo game design deve criar diferentes possibilidades de mundos, ambientes, sociedades, personagens e muitos outros elementos do jogo, tomando decisões e fazendo diferentes combinações para criar uma boa experiência de jogo para os jogadores.

No contexto específico dos JED, os interesses dos professores (pedagógico) e dos alunos (entretenimento) não são necessariamente os mesmos. Portanto, é preciso que essa informação seja levada em conta no desenvolvimento do game design. Kiili [2005] afirma que um jogo educacional deve oferecer aos jogadores desafios que correspondam às suas habilidades, não sendo nem muito fáceis e nem muito difíceis, para que seja gerada uma experiência agradável dentro do fluxo de progressão.

Através de um bom game design, os objetivos pedagógicos desejados podem ser inseridos no contexto do jogo, transformando essa tecnologia em ferramenta eficaz para o uso na educação. Neste sentido, o GDD continua sendo um documento essencial, visto que é nele que serão definidos todos os objetivos e contextos pedagógicos, bem como o formato e as estratégias que darão todo o suporte a fim de promover o engajamento e o aprendizado dos alunos [Fernandes et al. 2018].

Com o objetivo de auxiliar no processo de desenvolvimento e concepção dos JED, a literatura apresenta diversos modelos, frameworks e outros instrumentos que podem ser utilizados ao longo de todas as etapas, informando aos envolvidos quais elementos devem ser considerados na construção do jogo [Oliveira et al. 2018].

\subsection{Frameworks para Desenvolvimento de Jogos Educacionais Digitais}

Os jogos digitais são compostos por diversos elementos característicos que podem ser reaproveitados ao longo do seu desenvolvimento. Dessa forma, existem algumas metodologias que permitem a reutilização dessas características de forma simplificada. 
Dentre essas metodologias, uma das mais aceitas e utilizadas são os frameworks, instrumentos que integram a reutilização de códigos ou conceitos.

Um framework conceitual é um conjunto de ideias e conceitos que se interrelacionam para descrever como um sistema deve se comportar, se parecer e ser compreendido pelos usuários da maneira pretendida [Preece et al. 2005].

$\mathrm{Na}$ indústria de jogos, um dos frameworks mais conhecidos e utilizados é o MDA (Mechanics, Dynamics and Aesthetics ou Mecânicas, Dinâmica e Estética), desenvolvido por Hunicke et al. [2004] com o objetivo de diminuir as dificuldades do desenvolvimento de jogos digitais e promover uma melhor comunicação entre os usuários e desenvolvedores.

Os frameworks se inserem nas diferentes etapas do desenvolvimento, dependendo das necessidades do jogo. Alguns são usados apenas na etapa de concepção, enquanto outros são usados ao longo de todo o processo de desenvolvimento. Também variam de acordo com o gênero, público-alvo ou conteúdo a ser trabalhado, podendo ser aplicado a um segmento genérico ou em áreas mais específicas. No contexto do desenvolvimento de JED, eles podem indicar para a equipe quais os elementos que devem ser considerados na construção do jogo, o que envolve tanto elementos de entretenimento quanto conteúdo pedagógico.

Oliveira et al. [2018] trazem em seu estudo uma revisão sistemática, analisando treze frameworks para desenvolvimento de jogos educacionais, considerando as características de aplicação, ensino, ciclo de vida, elementos pedagógicos e de jogabilidade. A partir desse estudo, alguns frameworks analisados se mostraram mais relevantes na etapa de concepção de JED, quais sejam: o framework Four-Dimensional [Freitas e Jarvis 2006] e o framework Design, Play and Experience [Winn 2009].

O framework Four-Dimensional apresenta quatro elementos considerados importantes na produção de um JED, sendo eles: (1) Contexto, (2) Aprendiz, (3) Representação e (4) Pedagogia. O primeiro é referente ao contexto sobre a aplicação do jogo, devendo considerar, por exemplo, a infraestrutura e os recursos técnicos. O segundo elemento está relacionado ao público-alvo a quem o jogo se destina (alunos ou professores), destacando a importância de definir suas características, como dados demográficos e nível de conhecimento. O terceiro elemento está mais relacionado ao visual do jogo e seus elementos de design. Enfim, o quarto elemento é referente a como o conteúdo pedagógico será abordado a fim de promover a aprendizagem do público.

O framework Design, Play and Experience foi elaborado tomando como base o framework MDA com a integração de objetivos educacionais. Assim, além dos elementos de mecânicas, dinâmica e estética, também são utilizados os conteúdos pedagógicos. Para a concepção do jogo, seguem três etapas sequenciais, sendo elas: (1) Design (projetar), (2) Play (jogar) e (3) Experience (experiência). A primeira etapa é de estruturação do jogo, considerando os elementos que serão inseridos e o conteúdo que será trabalhado. A segunda etapa se refere a utilização do jogo, isto é, ao ato de jogar. Enfim, a terceira etapa reflete diretamente nas anteriores pois considera que, a partir do sucesso das primeiras etapas, é gerada uma boa experiência de jogo.

Os frameworks analisados por Oliveira et al. [2018] apresentam elementos e etapas relevantes para a concepção de JED. No entanto, não se mostram completos o suficiente para auxiliar em todo o game design do jogo, na fase de pré-produção. 
Por esta razão, um framework mais recente, intitulado PlayEduc [Barbosa e Madeira 2019], foi levado em consideração devido a sua completude e disponibilização de instrumentos considerados essenciais para o game design de JED. Este framework se baseia em três pilares fundamentais para o sucesso de um JED: a Psicologia, a Pedagogia, e o Design.

\subsection{PlayEduc: Um Framework Conceitual para o Design de JED}

PlayEduc é um framework conceitual para auxiliar equipes no processo de desenvolvimento de JED, se inserindo na etapa de pré-produção, especialmente na concepção do jogo, servindo como um guia para estimular o debate em torno dos diversos elementos relacionados ao game design.

Ele permite dar uma visão abrangente sobre os principais elementos inerentes aos jogos e ao aprendizado, tendo sido elaborado levando em consideração três pilares: a Psicologia, relacionada ao sentimento de imersão (entretenimento); a Pedagogia, referente ao processo de ensino e aprendizagem (instrução); e o Design, referente aos recursos de jogos que promovem uma boa jogabilidade [Barbosa e Madeira 2019]. Cada um dos pilares é constituído de 7 elementos essenciais para proporcionar o engajamento do jogador ao longo de uma partida de jogo, de forma a equilibrar o entretenimento com a aprendizagem, conforme apresentado na Tabela 1.

Tabela 1. Elementos Essenciais do framework PlayEduc. Fonte: Barbosa e Madeira, 2019

\begin{tabular}{llll}
\hline \multicolumn{1}{l}{ Pilares } & \multicolumn{1}{l}{ Psicologia } & \multicolumn{2}{l}{ Pedagogia } \\
\hline & 1. Imersão & 1. Expectativa & 1. Personagem \\
Elementos & 2. Evolução & 2. Recuperação & 2. Narrativa \\
Essenciais & 3. Realização & 3. Estímulo & 3. Câmera \\
& 4. Escassez & 4. Aprendizado & 4. Controle \\
& 5. Criatividade & 5. Performance & 5. Gráfico \\
& 6. Socialização & 6. Avaliação & 6. Percurso \\
& 7. Propriedade & 7. Retenção & 7. Complexidade \\
\hline
\end{tabular}

Analogamente, pode-se dizer que o PlayEduc funciona como uma bússola, servindo de instrumento para guiar as equipes de desenvolvimento em um processo estruturado e fundamentado, favorecendo uma cadeia de benefícios em todo o processo de desenvolvimento. Como principal produto, o PlayEduc oportuniza a concepção de um Educational Game Design Document (EGDD ou Documento de Game Design Educacional), que deve congregar todas as informações obtidas através da aplicação dos elementos essenciais, sendo considerado um documento de grande valor para todo $\mathrm{o}$ processo.

\subsubsection{Pilar da Psicologia}

O pilar da Psicologia é fundamentado na Teoria do Fluxo [Csikszentmihalyi 1997], relacionada à psicologia motivacional, e no framework Octalysis [Chou 2014], relacionado à gamificação, apresentando 7 elementos considerados essenciais no game design de um JED, sendo eles: 
1. Imersão: $\mathrm{O}$ jogo deve encorajar o envolvimento do jogador, buscando atrair ao máximo sua atenção. Ter conhecimento sobre o perfil do jogador, suas preferências e interesses é uma boa forma de conceber um produto que tenha uma melhor aceitação;

2. Evolução: O jogo deve promover uma evolução progressiva do jogador. Este aspecto contribui para que o jogo não se torne monótono, já que o sentimento de expectativa, gerado por novas descobertas, motivam o jogador;

3. Realização: O jogador deve experienciar o sentimento de conquista ao longo das várias fases do jogo. É importante definir objetivos claros e atingíveis, que alinhem as habilidades do jogador com as mecânicas do jogo, estabelecendo um processo de evolução natural, considerando que o sentimento de conquista deriva do sentimento de superação;

4. Escassez: O sentimento de tensão ou exclusividade experimentado pelo jogador contribui para um maior envolvimento. Promover esse sentimento no jogador, através de estratégias como o controle de tempo, recursos, habilidades, etc, aumenta seu nível de concentração;

5. Criatividade: $O$ jogo deve incentivar a criatividade do jogador, principalmente através da liberdade de escolha. Por exemplo, promovendo desafios secundários opcionais, caminhos alternativos e habilidades com vantagem temporária;

6. Socialização: Disponibilizar um espaço de interação entre os jogadores, seja online ou não, tende a aumentar o nível de interesse e engajamento;

7. Propriedade: $\mathrm{O}$ jogo deve promover ao jogador um mecanismo de propriedade. Este elemento está relacionado as mecânicas nas quais o jogador pode construir ou coletar algo.

\subsubsection{Pilar da Pedagogia}

O pilar da Pedagogia é fundamentado no design instrucional a partir da Teoria de Aprendizagem de Gagné [Gagné et al. 1992], e seus 7 elementos considerados essenciais aos JED são:

1. Expectativa: O jogo deve promover um contexto para o conteúdo educacional que será trabalhado. É recomendado implementar este elemento através de uma contextualização, na qual o jogador será apresentado ao conteúdo educacional de forma abrangente, mas dentro de um contexto;

2. Recuperação: O jogo deve resgatar do próprio jogador, os fundamentos do conteúdo educacional a ser trabalhado. O resgate desses conceitos relacionados é fundamental para o processo de aprendizagem, uma vez que serão utilizados cognitivamente para a consolidação das novas informações;

3. Estímulo: O jogo deve proporcionar elementos básicos para que o jogador entenda o objeto principal de aprendizagem. Os fundamentos do conteúdo educacional principal devem ser resgatados ou apresentados ao jogador, devido a sua grande relevância no processo;

4. Aprendizagem: $O$ jogo deve abordar de forma objetiva o seu conteúdo educacional. A definição do conteúdo de forma específica facilita a sua identificação no contexto do jogo e possibilita ao jogador e a outros envolvidos analisar e perceber o impacto que o jogo tem no processo de aprendizagem;

5. Performance: $O$ jogo deve promover feedbacks de aprendizagem contínuos. Este elemento destaca a importância de se ter uma ferramenta de avaliação e feedback 
sobre o aprendizado do jogador, que pode ser apresentado na câmera principal ou dentro dos menus;

6. Avaliação: O jogo deve possibilitar a correção/recuperação de uma ação dentro do jogo, principalmente relacionada ao conteúdo educacional. É fundamental que o jogador tenha a oportunidade de retomar uma ação de aprendizagem, corrigindo possíveis erros e consolidando as novas habilidades educacionais aprendidas;

7. Retenção: $O$ jogo deve oportunizar uma relação entre o conteúdo educacional com a vida real (cotidiano do aluno-jogador). Quando o conteúdo educacional é relacionado com as ações do dia a dia, o processo de retenção de informações se torna mais sólido.

\subsubsection{Pilar do Design}

O pilar do Design é fundamentado na Teoria dos Três C's de Rogers [2010] e nos Átomos do Design de Games de Schuytema [2017], com seus 7 elementos apresentados abaixo:

1. Personagem: Um personagem propicia a empatia do jogador, pois pode naturalmente trazer com ele uma narrativa e até objetivos e desafios no jogo. Muitos jogadores se envolvem profundamente com o personagem do jogo e tal elemento não pode ignorado;

2. Narrativa: Uma narrativa envolvente contribui com a promoção de um maior interesse do jogador. Questões como definir o propósito principal do personagem, os caminhos que ele deverá seguir, os desafios que ele enfrentará e qual será sua recompensa, são excelentes estratégias para a construção desse elemento;

3. Câmera: A câmera deve ser objetiva e apresentar na tela as principais informações para o jogador em tempo real. Fatores relacionados a esse elemento são o ângulo de visualização do jogador/personagem, o tamanho dos objetos e das fontes apresentados na tela, o design responsivo e a organização dos menus, objetos e outras informações relevantes sobre o jogo;

4. Controle: As mecânicas do jogo devem proporcionar uma experiência agradável e próxima a realidade. Conhecer o perfil do jogador, conduzir testes de jogabilidade e ouvir os feedbacks do jogador, são estratégias usadas para implementar controles mais intuitivos e amigáveis, gerando uma boa experiência;

5. Gráfico: Os gráficos estão relacionados a cenários, estilo artístico, efeitos especiais, etc, e devem atender as necessidades do jogo. Sempre é possível criar algo original. Um jogo com sua própria identidade aumenta a empatia, desperta a curiosidade e reduz comparações;

6. Percurso: O jogador deve estar completamente consciente de qual percurso deve seguir no jogo. Mas proporcionar percursos e rotas secundárias aumenta as possibilidades de entrar em fluxo e enriquece a experiência;

7. Complexidade: $O$ jogador deve se sentir capaz de realizar e completar os desafios propostos pelo jogo. Os níveis devem ser desenvolvidos considerando duas frentes: os desafios físicos, como barreiras, puzzles, estratégias, inimigos, chefões, etc, e os desafios educacionais, que envolvem o conteúdo educacional.

\subsubsection{Documento de Game Design Educacional}

O Documento de Game Design Educacional (EGDD) é o principal produto do PlayEduc. Ele se assemelha ao GDD, mas acrescenta o aspecto educacional para tornar o processo adaptado aos JED. 
Desta forma, trata diversas informações importantes referentes à descrição sobre o conteúdo educacional, contando com a definição das competências educacionais, o balanceamento educacional, a complexidade e a forma de progressão do conteúdo educacional, entre outros aspectos de grande importância para a produção de um JED, visando o design de um jogo melhor idealizado, construído e testado.

Espera-se que a equipe que opte pela utilização do framework PlayEduc tenha um maior ganho de qualidade e eficiência, sobretudo na fase mais crítica e fundamental do desenvolvimento do jogo que é a pré-produção.

Para facilitar e popularizar a utilização do PlayEduc na prática, os elementos essenciais foram organizados em 3 formulários, cada um tratando um pilar específico, disponibilizados por Barbosa e Madeira [2019] no endereço https://goo.gl/gHRAxZ. Esses documentos são estruturados para serem utilizados em duas etapas sequenciais, quais sejam:

1. Aplicação dos formulários essenciais com toda a equipe envolvida no desenvolvimento do jogo na etapa de pré-produção, a fim de compor o maior número de sugestões e estratégias para serem empregadas, preferencialmente integrando uma amostra do público-alvo (design imersivo). Esta etapa envolve brainstormings e muita criatividade, orientados pelos elementos essenciais do PlayEduc. Tem-se consequentemente os formulários essenciais preenchidos como produto final desta etapa, resultando numa documentação dos principais elementos e rumos do jogo;

2. Junção dos produtos gerados na etapa anterior com a proposta de arcabouço do EGDD, levando a equipe de desenvolvimento a dispor das informações essenciais para compor a primeira versão do documento que conterá todas as informações sobre o jogo, sendo um referencial para toda a equipe. Assim, o EGDD passa a ser utilizado como guia para balancear os esforços, levando em conta os aspectos indicados pelos três pilares que, de forma conjunta, visam aumentar a probabilidade do JED desenvolvido atingir o seu objetivo. Esta etapa pode ser desenvolvida pela equipe executiva de desenvolvimento do jogo, preferencialmente com pelo menos um integrante das etapas de desenvolvimento (programador, artista, roteirista, educador, etc.). Ela tem a primeira versão do EGDD como produto final.

A Figura 4 apresenta, de maneira mais intuitiva, uma visão geral dos componentes do PlayEduc, bem como uma visão prática das etapas de execução, oferecendo um modelo (arcabouço) de forma a orientar a equipe na finalização da primeira versão do EGDD, que consequentemente encerra a fase de pré-produção. 


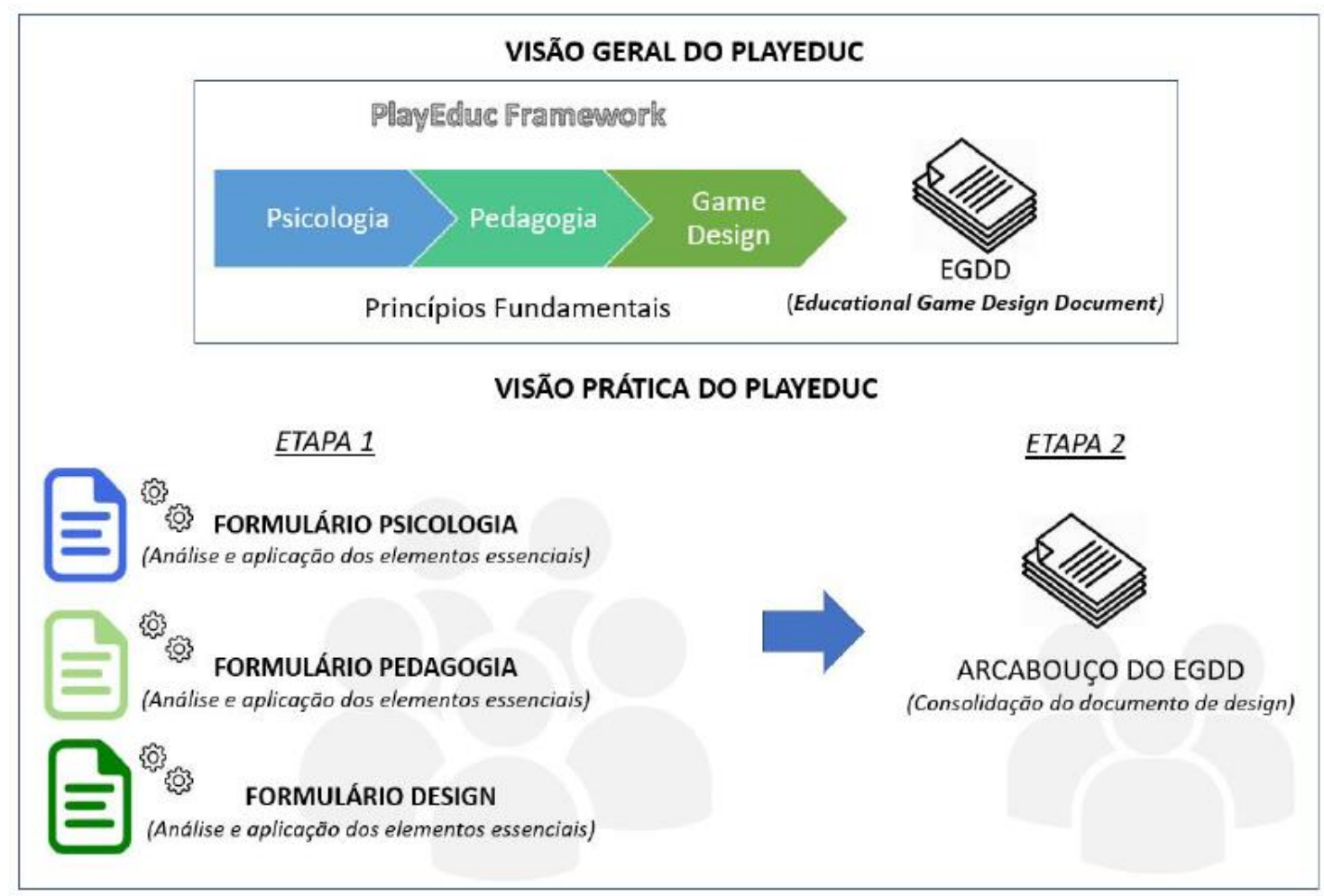

Figura 4. Visão geral do framework PlayEduc. Fonte: Os autores com base em Barbosa e Madeira, 2019

\subsection{Importância de um Pensamento Estruturado no Game Design de JED}

O processo de desenvolvimento de um JED segue uma etapa sequencial que inicia na préprodução, com a estruturação do game design, definindo todos os elementos que farão parte do produto para promover uma boa experiência de aprendizado ao aluno-jogador, elementos que influenciam diretamente no sucesso do jogo.

Dessa forma, para facilitar o processo de game design se faz necessário o uso de uma ferramenta que auxilie a equipe nesta etapa, guiando todo o processo. O framework PlayEduc se apresenta como uma alternativa interessante neste sentido, já tendo sido empregado eficazmente como guia no desenvolvimento do jogo Pharos, um JED para o ensino e aprendizagem da Matemática [Aires et al. 2019], que foi premiado em primeiro lugar no II Workshop de Inovação da CAPES [CAPES 2019].

No entanto, o PlayEduc pode não atingir todo o seu potencial se for utilizado por equipes que não tenham conhecimento prévio sobre mecânicas e estratégias de jogos, pois a equipe pode não conseguir elaborar e sugerir estratégias adequadas e relevantes para cada um dos elementos apresentados pelo framework.

Além disso, no desenvolvimento de JED é muito importante que a equipe tenha o público-alvo (alunos e professores) como elemento central no processo de desenvolvimento, considerando todas as suas características e identificando seus interesses e necessidades pois, quando isso não é feito, resulta muitas vezes na nãoaceitação do jogo pelo público-alvo. Portanto, é indicado que o emprego do PlayEduc seja feito em conjunto com alguma metodologia de construção de pensamento estruturado, levando em consideração o público-alvo antes de definir as estratégias para cada um dos seus elementos [Aires et al. 2020]. 
Neste contexto, a abordagem Design Thinking para Educadores se mostra como uma excelente opção, visto que coloca o usuário (aluno ou professor) no centro das atenções para guiar as tomadas de decisão a fim de propor soluções bem adaptadas aos problemas tratados pelos JED.

O Design Thinking é um processo de design que promove a construção do pensamento para a obtenção de ideias inovadoras que solucionem desafios, através do entendimento das dores dos usuários e do contexto do problema [Brown 2009].

O Design Thinking para Educadores (DTE) faz uso da metodologia do Design Thinking aplicada a solução de desafios enfrentados no âmbito da educação, pelos professores e escolas, sendo um modelo centrado no ser humano, colaborativo, otimista e experimental, que permite a liberdade de errar e aprender com os erros através de novas ideias e feedbacks recebidos de outras pessoas levando a reflexão sobre essas ideias [Educadigital 2014].

A abordagem é composta de cinco fases sequenciais que auxiliam desde a identificação de um desafio até a definição e construção de uma solução para ele. As etapas são a Descoberta, a Interpretação, a Ideação, a Experimentação e a Evolução (Figura 5), conforme detalhadas a seguir:

1. Descoberta: Tem o objetivo de identificar e entender o problema educacional a ser solucionado por uma equipe multidisciplinar que trabalhará na busca de uma solução, debatendo, compartilhamento ideias, identificando e realizando entrevistas com o público-alvo, efetuando pesquisas sobre o problema, levantando inspirações e ideias para possíveis soluções criativas que podem estar dentro ou fora do contexto do problema;

2. Interpretação: Visa analisar e sumarizar as ideias coletadas na etapa anterior, gerando insights importantes para a proposta de uma solução. Essa interpretação pode ser feita através da organização e categorização dos dados e compartilhamento de experiências, podendo utilizar ferramentas e métodos auxiliares ao processo, como por exemplo mapas de empatia e mapas conceituais, selecionando todos os insights advindos da interpretação, que podem ser transformados em possíveis ações;

3. Ideação: Tem o objetivo de gerar, reaproveitar e descartar ideias para resolução dos problemas, podendo ser feita através de brainstormings com toda a equipe, compartilhando ideais sem julgamentos, concebendo soluções e selecionando aquelas consideradas promissoras que devem ser levadas para a próxima etapa do processo;

4. Experimentação: É focada em transformar as ideias em soluções palpáveis, através da criação de esboços, modelos ou protótipos virtuais ou em papel que são testados pela equipe e pelos usuários, a fim de receber feedbacks levados em consideração para o refinamento daquela solução;

5. Evolução: Envolve o planejamento dos próximos passos, comunicando a ideia às pessoas que podem ajudar a realizá-la, e documentando o processo para a construção do projeto idealizado. 


\section{Fases do processo Design Thinking}

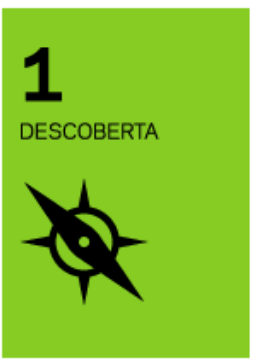

Eu tenho um desafio.

Como posso abordá-lo?

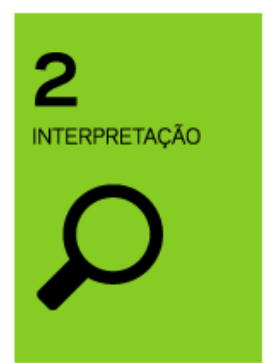

Eu aprendi alguma coisa.

Como posso interpretá-la?

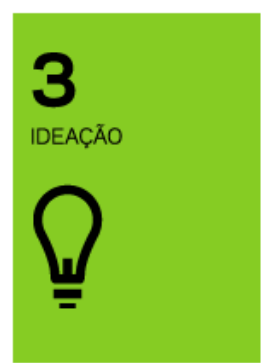

Eu vejo uma

oportunidade.

Como posso criar?

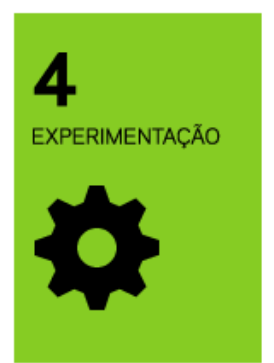

Eu tenho uma

ideia.

Como posso

concretizá-la?

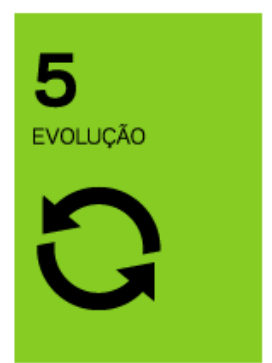

Eu experimentei

alguma coisa

nova.

Como posso aprimorá-la?

Figura 5. Fases do Processo de Design Thinking para Educadores. Fonte: Educadigital, 2014

A utilização em conjunto das etapas do DTE e dos elementos do PlayEduc, permite que a equipe de desenvolvimento do JED elabore ideias e desenvolva estratégias adequadas ao desenvolvimento de um JED que solucione o seu problema, atendendo as necessidades do seu público.

\subsection{Metodologia DTE e PlayEduc Aplicados no Design de Jogos Educacionais Digitais Inovadores e Instigantes}

A metodologia que alia o Design Thinking para Educadores ao framework PlayEduc garante uma maior produtividade da equipe no Game Design do JED, melhorando a comunicação e estimulando o trabalho em equipe, o pensamento lógico, a criatividade e a resolução de problemas, características indispensáveis em uma equipe na produção de jogos.

Para isso, o PlayEduc deve ser utilizado como recurso norteador nas fases de Descoberta, Interpretação e Ideação, pois entende-se que essas fases objetivam gerar soluções para um problema, e assim auxiliam na geração de estratégias para o jogo, ou seja, na concepção do mesmo. Nas fases de Experimentação e Evolução é dispensável o uso do framework e, por isso, elas estão fora do escopo abordado nessa metodologia.

Essa metodologia pode ser aplicada em um ciclo em que a equipe utiliza o PlayEduc como guia em cada fase do DTE, de forma sequencial (Figura 6). Isto é, os formulários do framework são aplicados para que cada um dos seus elementos seja utilizado como base na realização das pesquisas sugeridas na fase de Descoberta, gerando questionamentos e ideias. O processo avança para a etapa de Interpretação apenas quando finalizar a pesquisa e o levantamento de todos os elementos das três áreas do framework, ou seja, levantar ideias de estratégias para os 21 elementos. Esse formato é interessante pois engloba os elementos como um todo, gerando ideias diferentes nas três áreas para a concepção do jogo. 


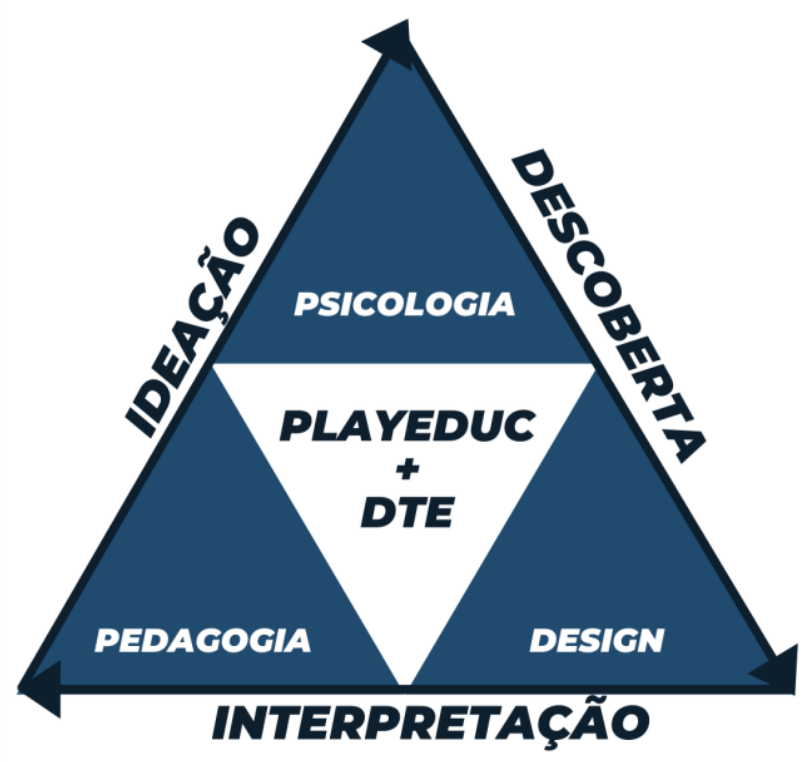

Figura 6. Modelo integrado entre PlayEduc e DTE

\subsubsection{Fase de Descoberta}

A fase de descoberta objetiva entender a problemática central de educação a ser solucionada, identificando oportunidades e formas de desenvolver uma solução com auxílio de um JED.

Para esta etapa, a equipe de desenvolvimento realiza diversas reuniões de brainstorming e também diferentes pesquisas a fim de coletar o maior número de informações sobre o problema a ser solucionado, criando um documento de referências com diferentes estratégias de ideias de solução.

Assim, alguns passos devem ser seguidos para um maior aproveitamento e levantamento de referências nesta fase, sendo eles: (1) Identificação do público-alvo, (2) Definição da problemática e limitações, e (3) Pesquisa de referência guiada.

A etapa de identificação do público-alvo é indispensável para a metodologia, visto que os interesses do aluno e do professor devem ser considerados para a concepção de todo o JED.

As equipes fazem uso de um formulário de briefing do público para desenhar quais são os problemas que eles enfrentam, quais são os interesses deles, que tipo de jogos eles jogam, qual plataforma (desktop ou mobile) eles mais utilizam, o que eles assistem, que tipo de conteúdos são disponibilizados para a sua faixa etária, além de outras informações que se mostrem necessárias. Esses dados são importantes para nortear o estilo e formato de jogo que agrada a esse público, para tomar como base no desenvolvimento do jogo educacional.

Na etapa de definição da problemática e limitações, os problemas que envolvem o público definido na etapa anterior são listados e analisados, e um dos problemas é escolhido para desenvolver um JED como possibilidade de solução. Assim, nesta etapa também são realizadas pesquisas e observações para melhor entender o problema.

A equipe também deve analisar as limitações técnicas, de infraestrutura e aplicação do jogo com o público, verificando, por exemplo, onde o JED será utilizado 
tanto a nível de espaço físico, quanto de plataforma. Esses dados são importantes para definir o aporte técnico do jogo a ser desenvolvido, e o que deve ser pensado de acordo com as limitações existentes para que a sua utilização seja viabilizada.

A última etapa é a de pesquisa de referência guiada, em que, utilizando o PlayEduc como guia, a equipe perpassa por cada um dos 21 elementos apresentados no framework, realizando pesquisas sobre estratégias e ideias que podem ser inseridas no jogo. $\mathrm{O}$ formato de pesquisa é de livre escolha da equipe, podendo ser pesquisas na internet, pesquisas de campo, pesquisa desk, etc.

A equipe preenche os formulários do PlayEduc adicionando anotações sobre as ideias elencadas para cada elemento, inserindo referências como links e imagens. $\mathrm{O}$ objetivo desta etapa é coletar o maior número de dados sobre os elementos, criando um banco de referências com diversas opções de estratégias que podem vir a ser utilizadas no jogo.

Ao realizar as pesquisas, a equipe deve direcionar suas buscas de acordo com os dados coletados no documento de briefing do público, buscando por jogos e conteúdos de interesse da faixa etária, bem como quais as habilidades, competências e conteúdos pedagógicos que o público está desenvolvendo na escola. No entanto, as buscas não devem se limitar a isso, visto que ideias inovadoras podem surgir de outros contextos diferentes do senso comum, como através de músicas, filmes e animações, ou até mesmo dos próprios livros didáticos.

Ao final da fase de Descoberta, as equipes têm como resultado o público-alvo delimitado, a problemática definida, as limitações listadas e os formulários do PlayEduc preenchidos com diferentes referências de possibilidades e ideias de estratégias que podem ser utilizadas em seus jogos, para assim prosseguirem para a próxima fase.

\subsubsection{Fase de Interpretação}

$\mathrm{Na}$ fase de interpretação, todas as informações coletadas na fase anterior são sintetizadas e analisadas para um entendimento maior sobre o problema e possíveis soluções. A equipe também realiza algumas reuniões de brainstorming para discutir sobre as referências levantadas e consideradas mais relevantes para a concepção do jogo educacional que pretende desenvolver.

A partir das referências, a equipe seleciona quais as estratégias, tanto relacionadas ao entretenimento quanto educacionais, serão inseridas no JED e inicia o detalhamento delas de acordo com os elementos do PlayEduc. Assim, faz inferências e convergências entre suas áreas, como por exemplo, definindo possibilidades sobre a narrativa do jogo, narrativa dos personagens, mecânicas dos personagens, etc.

Além disso, detalha os conteúdos pedagógicos que serão tratados e como eles podem ser contextualizados aos outros elementos, como por exemplo integrando o conteúdo educacional na mecânica dos personagens, ou na própria câmera do jogo.

Ao final da etapa de interpretação, a partir do detalhamento dos formulários do PlayEduc, a equipe deve estar alinhada e mais direcionada sobre as definições do jogo, já estruturando as narrativas, personagens e suas habilidades, mecânicas, gráficos, conteúdos pedagógicos e todos os outros elementos apresentados pelo PlayEduc. A partir daqui, pode seguir para a próxima fase. 


\subsubsection{Fase de Ideação}

$\mathrm{Na}$ fase de ideação, a equipe estrutura o documento base de todo o jogo a partir do Documento de Game Design Educacional proposto por Barbosa e Madeira [2019].

Para isso, a equipe deve preencher o EGDD de acordo com as estratégias elencadas e detalhadas no PlayEduc, adicionando mais informações e estruturando-as no formato que serão inseridas no jogo, de forma que a equipe esteja sempre alinhada sobre as estratégias adotadas.

No documento também devem ser inseridas imagens e links de referência do que se quer adicionar no jogo e, quando estes começarem a ser implementados, as imagens e links devem ser atualizados para aqueles próprios da identidade do jogo. Também devem ser adicionados esboços, mockups de tela, fluxograma de percurso de cena, desenhos de funcionamento dos desafios educacionais e outros recursos que auxiliem em uma melhor visualização sobre a ideia do jogo a ser desenvolvido.

Ao final desta fase a equipe terá toda a concepção do seu JED delimitada e o documento base estruturado, contendo todos os elementos considerados essenciais para o sucesso de um jogo para educação. Com esse guia, pode prosseguir para as próximas etapas de execução do projeto.

\subsubsection{Fases de Experimentação e Evolução}

Entende-se que as fases de experimentação e evolução estão mais relacionadas à etapa de produção do JED, e por isso não entram no escopo deste estudo que tem como foco a construção do Game Design na etapa de pré-produção.

No entanto, é sugerido que a equipe prossiga nas etapas de desenvolvimento de JED e fases do DTE, construindo o jogo que foi concebido e delimitado no EGDD. É aconselhado que a fase de experimentação seja iniciada, se possível, com a prototipação em baixa definição (em papel) de algumas partes do jogo, que podem ser desenvolvidas no formato de storytellings. Esses protótipos devem ser testados com o público-alvo a fim de obter feedbacks sobre a solução proposta. Em seguida, pode ser desenvolvido um protótipo digital para também ser testado com o público a fim de validar a solução que está sendo elaborada.

A partir dos feedbacks e aprendizados com o desenvolvimento do JED, o produto deve ser atualizado e reestruturado na fase de evolução, levando em consideração as críticas e sugestões dadas pelo público. Dessa forma, o risco da não aceitação do jogo é minimizado, pois o usuário participa ao longo de todo o processo de concepção, tendo suas opiniões consideradas.

\subsection{Considerações Finais}

Este capítulo apresentou uma abordagem de aplicação integrada do framework PlayEduc com a metodologia do Design Thinking para Educadores, com o objetivo de auxiliar equipes no processo de desenvolvimento de JED, uma vez que essa categoria de jogos é considerada uma estratégia instrucional interessante e eficaz para os alunos nativos digitais que exigem um aprendizado cada vez mais dinâmico.

No entanto, diferentemente dos jogos desenvolvidos com foco totalmente voltado para o entretenimento, os jogos educacionais digitais utilizados nos dias de hoje em salas 
de aula tendem a geralmente não motivar os alunos. Este fator pode estar relacionado, principalmente, ao fato que esses jogos apresentam problemas em sua concepção, pecando na falta de elementos primordiais do universo dos jogos voltados ao puro entretenimento, em conjunto com os aspectos pedagógicos que se deseja atingir.

O game design se mostra como uma etapa primordial no planejamento de um JED, apresentado diversos modelos e frameworks para auxiliar nessa etapa. O framework PlayEduc se insere neste contexto como uma ferramenta capaz de alinhar de forma mais intuitiva as três áreas consideradas essenciais na concepção de um JED (Psicologia, Pedagogia e Design), servindo como um guia para auxiliar as equipes no design do jogo.

Para potencializar a aplicação do PlayEduc, a abordagem Design Thinking para Educadores foi integrada ao processo de desenvolvimento com o intuito de construir o EGDD por meio de uma abordagem centrada no usuário. As fases dessa abordagem favorecem o surgimento de ideias para uma melhor estruturação do escopo do jogo, ou seja, de sua concepção. Essa integração se mostra como uma excelente solução para auxiliar as equipes na construção do game design dos JED, aumentando a produtividade e facilitando a compreensão sobre os elementos essenciais aos mesmos. Consequentemente, isso aumenta a probabilidade de obter sucesso no processo de desenvolvimento desta categoria de jogos, tornando-os mais interessantes aos olhos dos alunos e eficazes pedagogicamente aos olhos dos educadores.

\subsection{Agradecimentos}

O presente trabalho foi realizado com o apoio da Coordenação de Aperfeiçoamento de Pessoal de Nível Superior (CAPES) por meio do edital No 42/2017 de Educação na temática Jogos Virtuais.

\section{Referências}

Aires, S., Madeira, C., Ferreira, G., Nascimento, N. (2019) "Pharos: Um jogo digital para auxiliar no ensino de Matemática nos cursos de licenciatura da Universidade Aberta do Brasil". Anais do XVI Congresso Brasileiro de Ensino Superior a Distância (ESUD 2019), p.1461-1473.

Aires, S. F., Madeira, C. A. G. (2020) “Desenvolvimento de Jogos Educacionais Digitais: um Relato de Experiência com o Framework PlayEduc". RENOTE, 18(1).

Araújo, W. O., da Silva Aranha, E. H., Madeira, C. A. G. (2018) "Geração Procedural de Conteúdo Aplicada a Jogos Digitais Educacionais”. Jornada de Atualização em Informática na Educação, 7(1), 1-20.

Barbosa, J. (2018) "PlayEduc: um framework conceitual para desenvolvimento de jogos educacionais digitais”. Dissertação de Mestrado, Programa de Pós-graduação em Engenharia de Software, Universidade Federal do Rio Grande do Norte.

Barbosa, J., Madeira, C. (2019) "PlayEduc: A Conceptual Framework for the Development of Digital Educational Games". In the Proceedings of the IEEE 19th International Conference on Advanced Learning Technologies (ICALT 2019), p.103104. 
Battistella, P., Von Wangenheim, C. (2016) "Games for Teaching Computing in Higher Education: a Systematic Review". IEEE Technology and Engineering Education, 9(1):8-30

Brasil. Secretaria Especial da Cultura. (2018) " $2^{\circ}$ Censo da Indústria Brasileira de Jogos Digitais aponta crescimento de games no Brasil". Disponível em: $<$ http://www.sedetur.al.gov.br/servicos-internos/observatorio-da-economia-criativae-do-turismo/publicacoes-de-instituicoes-parceiras/censo-da-industria-brasileira-dejogos-digitais/send/62-censo-da-industria/136-2-censo-da-industria-brasileira-dejogos-digitais/>. Acesso em: 04 jan. 2020.

Brown, T. (2009) "Design Thinking: Uma Metodologia Poderosa para Decretar o Fim das Velhas Ideias". 272p, Alta Books.

CAPES (2019) "Workshop premia inovações tecnológicas para educação". Disponível em: $<$ https://www.capes.gov.br/36-noticias/10059-workshop-premia-inovacoestecnologicas-para-educacao $>$. Acesso em: 18 jul. 2020.

Chandler, H. M. (2012) "Manual de Produção de Jogos Digitais". Porto Alegre: Bookman.

Chou, Y. K. (2014) "Actionable Gamification: Beyond Points, Badges, And Leaderboards". 1th. Ed. Milpitas: Octalysis Media.

Costa, L. D. (2008) "O que os jogos de entretenimento têm que os jogos com fins pedagógicos não têm: princípios para projetos de jogos com fins pedagógicos". Dissertação Mestrado, Departamento de Artes e Design, Pontifícia Universidade Católica do Rio de Janeiro.

Csikszentmihalyi, M. (1997) "Finding Flow: The Psychology of Engagement with Everyday Life". 1st. ed. New York: Basic Books.

Educadigital, I. (2014) "Kit de Design Thinking para Educadores". Disponível em: $<$ http://www.dtparaeducadores.org.br/>. Acesso em: 01 jul. 2020.

Fernandes, K. T., Lucena, M. J. N. R., da Silva Aranha, E. H. (2018) "Uma Experiência na Criação de Game Design de Jogos Digitais Educativos a partir do Design Thinking”. Revista Novas Tecnologias na Educação (RENOTE), 16(1).

Freitas, S., Jarvis, S. A. (2006) "Framework for Developing Serious Games to meet Learner Needs". In: I/ITSEC. pp.1-11.

Gagné, R. M. et al. (1992) “Principles of Instructional Design”. Hbj College Publishers.

Gee, J. P. (2009a) “Bons video games e boa aprendizagem”. Perspectiva, 27(1), 167-178.

Hunicke, R., Leblanc, M.G., Zubek, R. (2004) "MDA: A Formal Approach to Game Design and Game Research". In: Proceedings of the AAAI Workshop on Challenges in Game AI. 2004. p. 1722.

Kiili, K. (2005) “Digital game-based learning: Towards an experiential gaming model”. Internet and Higher Education, 8(1):13-24.

Koster, R. (2013) “Theory of Fun for Game Design”. O’Reilly Media, 279p.

Mattar, J. (2010) "Games em Educação: Como os Nativos Digitais Aprendem”. São Paulo: Pearson Prentice Hall. 
Oliveira, R., Cardoso, R., Braga, J., Campos, R. (2018) "Frameworks para Desenvolvimento de Jogos Educacionais: uma revisão e comparação de pesquisas recentes". Anais do XXIX Simpósio Brasileiro de Informática na Educação (SBIE 2018).

Paz, I. L. (2019) "Ferramenta eMDAx - Proposta de framework de game design para jogos educacionais". Dissertação de Mestrado, Curso Design e Desenvolvimento de Jogos Digitais, Universidade Da Beira Interior.

PGB (2020) "Relatório Pesquisa Game Brasil 2020". Disponível em: $<$ https://pesquisagamebrasil.com.br/pt/pesquisa-game-brasil-2020/>. Acesso em: 04 out. 2020 .

Petri, G., Wangenheim, C., Borgatto, A. F. (2016) "MEEGA+: An Evolution of a Model for the Evaluation of Educational Games". Technical Report INCoD/GQS.03.2016.E, INCoD/INE/UFSC, Florianópolis/Brazil

Preece, J., Rogers, I., Sharp, H. (2005) "Design de Interação: Além da Interação HumanoComputador". Porto Alegre: Bookman.

Prensky, M. (2012) “Aprendizagem baseada em jogos digitais”. 1th. ed. São Paulo: Senac.

Prensky, M. (2001) “Digital Natives, Digital Immigrants”. [S.L.]. V. 9, N. 5.

Prieto, L. M. et al. (2005) "Uso das Tecnologias Digitais em Atividades Didáticas nas Séries Iniciais”. Revista Novas Tecnologias na Educação (RENOTE), 3(1):1-11.

Rogers, S. (2010). “Level Up! The Guide to Great Video Game Design”. 1st. ed. West Sussex: Wiley.

Santana, E. S. (2018) “O Uso de Jogo Educativo Lúdico para o Ensino e Aprendizado Utilizando a Ferramenta Scratch no Ensino Fundamental Regular". Encontro Internacional Virtual Educa Bahia, Salvador.

Savi, R., Ulbricht, V. R. (2008) "Jogos Digitais Educacionais: Benefícios e Desafios". Revista Novas Tecnologias na Educação (RENOTE), 6(2):1-10.

Superdata. A Nielsen Company. (2020a) "2019 Year In Review: Digital Games and Interactive Media". Disponível em: $<$ https://www.superdataresearch.com/reports/2019-year-in-review $>$. Acesso em: 04 out. 2020 .

Superdata. A Nielsen Company. (2020b) "Worldwide digital games market: August 2020". Disponível em: $<$ https://www.superdataresearch.com/blog/worldwide-digitalgames-market>. Acesso em: 04 out. 2020.

Schell, J. (2008). “The Art of Game Design: A book of lenses”. CRC press.

Schuytema, P. (2017) "Design de Games: Uma Abordagem Prática”. Cengage Learning.

Winn, B. M. (2009) “The design, play, and experience framework”. In: Handbook of research on effective electronic gaming in education. IGI Global. p.1010-1024. 